\title{
Research on Optimization of Selection Mechanism of Medical Advanced Talents
}

\author{
Yi Zhang ${ }^{1}$, Shidi Wen ${ }^{2}$ \\ ${ }^{1}$ Gannan Medical University, Ganzhou, Jiangxi, China, 341000 \\ ${ }^{2}$ Gannan Medical University, Ganzhou, Jiangxi, China, 341000 \\ hunter2011@foxmail.com
}

Keywords: Medical advanced talents, Recruitment mechanism, Selection mechanism.

\begin{abstract}
The talent resource, especially the advanced medical talent resources, is the key of competitive advantage for medical institutions. This paper firstly gives the concept of the Medical Advanced Talents, and then expounds the quality structure and its test methods of medical advanced talents, finally puts forward the suggestions of optimization of selection mechanism of medical high level talents in order to provide some references for the related researchers.
\end{abstract}

\section{Concept of Medical Advanced Talents}

Talents are the people who have certain professional knowledge or special skills, carry out creative work and contribute to the society. High level talents are the talents with excellent quality, advanced scientific and cultural knowledge. They are rich in innovation ability, can adapt to market competition quickly, and can make significant contribution to economic development and social progress. Advanced talents refer to the level of the higher level of outstanding talent, or in the professional front and in the domestic and foreign related fields with high impact. High level talents are scarce. Scarcity is the social needs, in the era of low productivity, social labor is mainly simple labor, and labor supply is almost unlimited. However, in today's and future high-tech era, the demand for high level professional talents is increasing, the acquisition of professional talents is not only dependent on the ability of people to obtain information, education, personal efforts, personal environment, opportunities and many other factors, but also has the inherent characteristics of long cycle. This objectively caused the lack of advanced talents extremely. The ratio of advanced professional talents is very low in enterprises and institutions.

\section{Quality Structure of Medical Advanced Talents}

Strong Medical Ethics. Medical ethics is the professional ethics of medical advanced talents, including scientific ethics of medical scientific research, medical life-saving humanitarian and the guidelines of treating patients as relatives for the work. The most valuable thing is in the world is the human's life. To be engaged in medical profession is undertaking a quite complex and sacred scientific work, and cannot be the slightest bit of false and any immoral behavior. Noble medical ethics, will make medical high-level personnel to the people's physical and mental health responsible for the high sense of responsibility, the people's needs as their first need to lift the people's sufferings as their moral responsibility, the patient is not rich and poor, caring, dedication and wisdom, treatment. Only by virtue of the high quality of medical staff, the essence of medical ethics is to protect and maintain social harmony and stability, maintain social harmony and stability, maintain social harmony and stability, maintain social harmony and stability. Moral character is an important feature of medical advanced talents.

Excellent Medical Skills. Medical moral models without the superb medical skills also cannot be the medical high level talents. Medical skills are the premise and basis of medical ethics. The doctor has not only humanitarian enthusiasm has also heal the wounded and rescue the dying, superb medical skill. This superb skill is a necessary condition to achieve his humanitarian. Medicine is an applied science, which mainly includes medical theory and medical practice. 
Medical discipline high level talented person should have the solid specialized theory basic knowledge and rich practical experience two essential conditions. With the rapid development of modern medicine, the lack of these two essential conditions, it is not possible to become outstanding medical disciplines high level talents. Any scientific innovation and development needs a strong theoretical knowledge and rich practical experience as the basis. It is very important to combine the abundant basic theory knowledge and the rich experience. Into the water without a source, medical practice is the direct basis for the development of medical science, high-level talents in medical discipline left the medical practice of medicine is non-existent. In turn, medical practice must be carried out under the guidance of a certain medical science, not blindly. The level of professional knowledge of basic theory is the premise of the decision of the high level talents in the field of science and the contribution of the scientific field. The theoretical knowledge and practical experience sare the important guarantee for the excellent medical skills.

Good Team Spirit. The talents engaged in the medical field without good team spirit are also not the medical advanced talents. In order to meet the objective requirements of the development of modern medicine, medical personnel's team cooperation consciousness in the practical work of more and more important. Medical high level talents should learn from each other, giving full play to the comparative advantage, have a good effect, in view of the requirements, medical high level talents in usual scientific research and practice in the process, of self-consciousness of team training is a required course. Through such a long and strict self-requirements and hospital organization in the team work atmosphere, they have strong team work ability. Doctors who want to cooperate with the medical treatment of patients, as a colleague to cooperate with other doctors' work, as the hospital staff should obey the arrangement, with the upper work. In such a complex environment, the doctor's personality may need to converge, if the nature of the line, the lack of cooperation spirit, will give the whole team of doctors and hospitals to develop and bring many troubles. If a doctor refuses to cooperate with other doctors, he cannot cure the patients effectively. Nobody considers him as the high level personnel in medical area.

\section{Test Methods of Medical Talents' Quality}

Written Examination. The written examination is to be measured by the evaluation of the unified time, unified location, unified requirements, through the form of a paper pen to complete the evaluation of the test. It is the evaluation of the standard of the evaluation of the object to be judged by the amount of knowledge, knowledge structure and knowledge level of a method. It is usually divided into two main types of examination and qualification examination written examination. The selection of the test is a "constant modulus reference" written examination, its main function is to distinguish, select, and distinguish between the candidates, the selection of outstanding talents. The qualification examination written examination, is the "target reference" written examination, its main function is to assess, identify, and test the quality of the candidates, whether to meet the level of a certain standard.

Interview Evaluation. Interview, also called interview evaluation, is to test the quality of the test personnel, ability and motivation of the interviewee through the observation and communication through the interviewee and interviewer. The validity of the interview depends on the experience of the Lord. Commonly used and recognized are structured interviews. The so-called structured interview, in accordance with the pre-determined content, procedures, evaluation criteria, score structure of the interview form, or, is the same as candidates, with the same tone and language, in the same order, ask the same question, according to the same standard score. The interview can measure the knowledge, skills, quality, practical ability (combined with certain situation simulation or task operation), practical experience, professional expertise, response ability, strain capacity, analysis and judgment and comprehensive ability, self-control ability, oral expression ability.

Psychology Test. Psychological test is a kind of concrete form of psychological measurement, which is the objective and standardized measurement of the behavior sample group. Psychological tests can be divided into different categories according to different standards. According to the specific object of the test, the psychological test can be divided into cognitive test and personality 
test. A battery of cognitive tests can be divided into achievement test (assessment of knowledge and skills, such as Stanford Achievement Test), IQ test (evaluation of cognitive activity in relatively stable behavioral characteristics, such as the Stanford Binet intelligence scale, Wechsler table) and aptitude test (evaluation of human cognitive potential). Personality tests can be divided into Attitude Test (such as the Likert type attitude scale) test, and interest tests, such as Edward hobby test and personality test (such as Cartel 16 factors test, management personnel personality test) and test of character (Lester moral test).

\section{Optimization of Selection Mechanism of Medical Advanced Talents}

Notice Synthetic Quality. Due to the importance of the synthetic quality, we must pay attention to the comprehensive quality of medical high level personnel selection."First learn to be a man, then learn how to learn, and finally learn to do things", "first ethics and second academics, pay attention to practical work, scientific research ability and clinical teaching work", "not only have the specific professional field, but also have the overall situation and strategic vision", these experts suggest not only shows the high level talents of high standards, strict requirements, but also for the further improvement of competency model provides a profound inspiration. On the basis of the existing work, to further investigate the ideological trend and depth of thinking and the depth of thinking, and the depth of the personality, psychology, ideas and ideas, as well as possible to improve the competency model. Qualitative methods mainly from qualitative aspects to grasp the object is in conformity with the standard from experience, intuition and other aspects of comprehensive grasp, with a certain flexibility and elasticity "quantitative is more focused on the objective and unified" first qualitative main is to do not pass the qualified personnel, quantitative methods can be difficult to choose the qualitative method, provide objective and unified standards. At the same time, the comprehensive evaluation of the content should be developed into a detailed, clear, workable index system, using a variety of evaluation means, the theory applied to medical personnel selection practice.

Improve Evaluation Mechanism. First, we must ensure that the selection and training of the process of fair and fair, open and fair can increase the level of beneficiaries, but also to consider the interests of the authorities and departments. Secondly, the main selection should fully understand the being evaluated comprehensive information, and listen to the opinions and suggestions of the front-line clinical staff engaged in. On the selection of subjects for a comprehensive and rational evaluation and some high level personnel tend to have a strong personality and unique way of doing things, the selection of main body should be long-term perspective, inclusive. Again, to perfect the system of personnel evaluation, such as introducing the multilateral evaluation mechanism, pay close attention to the views of the Department staff; build a platform for fair competition, so that scholars can be volunteered; implement trial period system, extend the inspection cycle and so on. Finally, standardize the examination system, will in the selection of medical high level talents, increase content of man-machine conversation examination, including foundation, related professional, professional, new progress, especially to solve the diagnosis and treatment of clinical difficulty diseases. Objective indicators, especially clinical technology should objective, quantitative and increase moral quality indicators, to the generation of test assessment, to ensure open and fair.

Strengthen Talents' Communication. On the one hand, it is necessary to continue to reduce the flow of medical personnel barriers, develop and improve the corresponding flow policies and supporting system, so that the outstanding talent is always able to take off and not the unknown. On the other hand, it's also necessary to increase the intensity of foreign exchange, multiple choices to send some talent to learn from advanced foreign medical institutions and the advanced ideas, knowledge and skills after the introduction of the domestic, to fully absorb and make it play an important role in actual utility. It is necessary to give full play and the use of knowledge talent, but also to protect, concise "in" the national characteristics. In addition to personnel interaction, in academic exchanges also have an international perspective, pay attention to overseas experience, overseas study or work experience is very helpful to deal with specific work. In the selection of 
medical advanced talents, we should be concerned about the publication of domestic scholars EI, SCI and other included original research papers.

Develop Broad Study. Training process should be given to support for high-level personnel to provide as many opportunities as possible to understand the advanced countries and regions of the advanced technology, improve the academic level of the professional, professional, ideological style of the middle and young, especially young backbone of targeted training, and promotion, so that the ultimate stand out. We provide a platform for development, training and opportunities for continuous learning and promotion, so that high levels of talent in the new environment with new ideas to arm themselves, and through regular training, internship opportunities to get sustained growth. In addition, and keep high level of work pressure; networking forum contend, improve the treatment, to give financial support etc. Anyway, the selection of medical high level talents should have long-term planning. It's helpful to set the training objectives, evaluation indicators and implement it into grassroots to form the selection system of medical advance talents.

\section{Conclusion}

Strong medical ethics, excellent medical skills and good team spirits are the characteristic of medical high level talents. To notice synthetic quality, improve evaluation mechanism, strengthen talents' communication and develop broad study will optimize the selection mechanism of medical advanced talents.

\section{References}

[1] R.X. Huang, Researchon Medical HighLevel Talents Acquisition, Retainingand Development Mechanism, Xiamen University, 2008.

[2] R.L. Zhao, Y.M. Wang, F.X. Guan, The Research of the Selection and Appointment Mechanism of High Level Talents in Medical Association, Henan Medical Research, 2(2013)135-137.

[3] J.M. Zhao, The Application of Competence Model in Advanced Medical Talent Recruitment, Chinese Hospitals, 12(2009)56-57.

[4] L. Wang, R.L. Shen, Creating the Mechanism of High-level Talent Evaluation in Medical University, Acta Universitatis Medicinalis Nanjing(Social Sciences), 12(2007)329-332. 